\title{
Preliminary study on the contribution of osmotic effects for the electrical resistivity of sands
}

\author{
Inês Borges ${ }^{1,2}$, Vikas Gingine ${ }^{3}$, and Rafaela Cardoso ${ }^{1,4^{*}}$ \\ ${ }^{1}$ IST, Universidade de Lisboa, Av. Rovisco Pais, 1, 1049-001 Lisbon, Portugal \\ 2 INESC-MN, R Alves Redol, 9, 1000-029 Lisboa Portugal \\ ${ }^{3}$ KLS Gogte Institute of Technology, Belagavi, 590008, India \\ ${ }^{4}$ CERIS, Av. Rovisco Pais, 1 1049-001 Lisbon, Portugal
}

\begin{abstract}
Electrical resistivity of soils can be used to evaluate the level of contamination in soils in geophysical prospection tests. The chemical composition of pore fluid also corresponds to a given water potential, named as osmotic suction. Therefore both electrical resistivity and osmotic suction can be related when soil is saturated. This paper investigates their relationship when the soil is not saturated. The osmotic suction and electrical resistivity were measured for uniform grading size samples of sand prepared with different concentrations of an ionic leachate from a real landfield. Both were measured also for the fluid with the different concentrations. Suction was measured for different degrees of saturation using the ionic fluid for the different concentrations. The soil osmotic suction is similar to the osmotic suction of the pore fluid independently from the degree of saturation, and the differences in electrical resistivity in the saturated samples and pore fluid alone as function of osmotic suction are related by a constant. Although pore fluid composition affects electrical resistivity, when evaluating the electrical resistivity considering the degree of saturation one should pay attention to factors that are related with matric suction instead of osmotic suction.
\end{abstract}

\section{Introduction}

Electrical resistivity can be used to evaluate the level of contamination in soils in geophysical prospection tests, because of the presence of ions and heavy metals [1]. Pore fluid has great influence in electrical resistivity of a soil sample, especially in granular soil samples [2] because solid particles (silica mainly) are non conductive and therefore electrical current flows only in the liquid phase. Electrical resistivity depends also on porosity and temperature besides the composition of the pore fluid and degree of saturation.

The chemical composition of pore fluid corresponds to a given osmotic water potential, also named as osmotic suction [3]. Therefore both electrical resistivity and osmotic suction can be related, in particular when soil is full saturated. This paper investigates their relationship when the soil is not saturated when there is still continuity of the liquid phase in the soil pores as illustrated in Figure 1.

An experimental study was performed where the osmotic suction and electrical resistivity were measured on uniform grading size samples of sand prepared with different concentrations of an ionic leachate from a real landfield. Measurements were done for different degrees of saturation using the ionic fluid for the different concentrations. Osmotic and matric suction were found considering these measurements and the values from the water retention curve of the material measured using distilled water. The paper ends discussing how electrical resistivity is affected by the degree of saturation in terms of soil suction measurements, and how osmotic suction affects electrical resistivity considering the presence of solid particles and their arrangement.

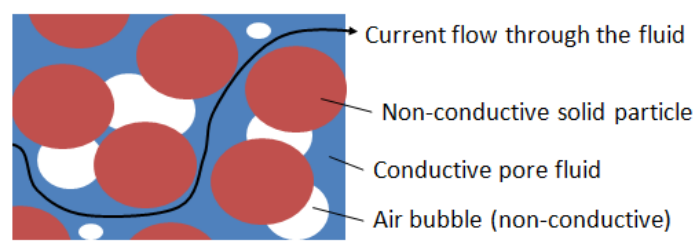

Fig. 1. Conduction of electrical current in unsaturated soils.

\section{Materials}

\subsection{Sand}

The material used is a river sand (reference APAS 20) commercial available in Portugal. Its grading size distribution is in Fig. 2. This is a clean sand, so there is no fine material $(0 \%$ material passing ASTM sieve \#200). The effective diameter is $D_{10}=0.5 \mathrm{~mm}$ and, accordingly with Unified Soil Classification System, APAS 20 classifies as poorly graded sand (SP). Specific gravity (Gs) is 2.68 and minerals present are quartz, zircon and tourmaline.

Corresponding author: rafaela@ civil.ist.utl.pt 
The samples studied were prepared with void ratio (e) of 0.72 corresponding to a relative density (Dr) of $50 \%$. For this void ratio the saturated water content $\left(\mathrm{w}_{\mathrm{sat}}\right)$ is $27 \%$.

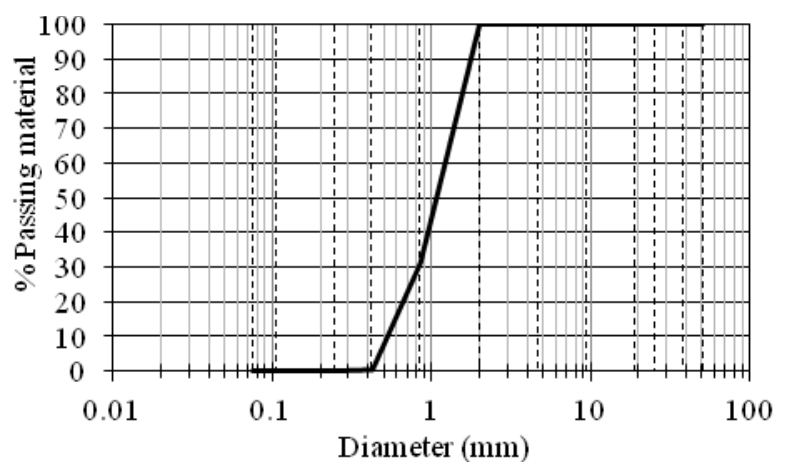

Fig. 2. Grain size distribution of APAS 20 sand.

\subsection{Leachate fluid}

The fluid used is leachate collected in a landfill from the Lisbon area, in Portugal. The major heavy metal and inorganic species concentrations in this leachate were analyzed and the concentration are present in Table 1. The concentration of heavy metal and ions present ensure that this is an electrical conductive fluid.

Table 1. Chemical composition of the leachate.

\begin{tabular}{|l|l|l|l|}
\hline \multicolumn{2}{|c|}{$\begin{array}{c}\text { Organic parameters/ } \\
\text { Compounds }\end{array}$} & \multicolumn{2}{c|}{ Heavy metals/ metals } \\
\hline \multicolumn{1}{|c|}{ Parameter } & $\mathrm{mg} / \mathrm{l}$ & \multicolumn{1}{|c|}{ Parameter } & \multicolumn{1}{c|}{$\mathrm{mg} / \mathrm{l}$} \\
\hline $\mathrm{COD}\left(\mathrm{O}_{2}\right)$ & 7100 & Copper $(\mathrm{Cu})$ & 0.009 \\
\hline BOD $\left(\mathrm{O}_{2}\right)$ & 1400 & $\begin{array}{l}\text { Chromium } \mathrm{VI} \\
(\mathrm{Cr}(\mathrm{VI}))\end{array}$ & $<0.0050$ \\
\hline TOC $(\mathrm{C})$ & 2350 & Calcium $(\mathrm{Ca})$ & 152 \\
\hline AOX $(\mathrm{Cl})$ & 1.21 & Lead $(\mathrm{Pb})$ & 0.04 \\
\hline $\begin{array}{l}\text { Ammoniacal } \\
\text { nitrogen }\left(\mathrm{NH}_{4}\right)\end{array}$ & 3200 & Manganese $(\mathrm{Mn})$ & 0.2973 \\
\hline Chlorides $(\mathrm{Cl})$ & 3500 & Mercury $(\mathrm{Hg})$ & $<0.01$ \\
\hline Sulphates $\left(\mathrm{SO}_{4}\right)$ & 4100 & Arsenic $(\mathrm{As})$ & $<0.01$ \\
\hline Sulphides $(\mathrm{S})$ & 15,8 & Nickel $(\mathrm{Ni})$ & 0.22 \\
\hline Fluorides $(\mathrm{F})$ & 0.44 & Zinc $(\mathrm{Zn})$ & 0.50361 \\
\hline Cyanides $(\mathrm{CN})$ & 0.02 & Iron $(\mathrm{Fe})$ & 7.59 \\
\hline Nitrates $\left(\mathrm{NO}_{3}\right)$ & 38 & Sodium $(\mathrm{Na})$ & 2432 \\
\hline Nitrites $\left(\mathrm{NO}_{2}\right)$ & $<0.10$ & Potassium $(\mathrm{K})$ & 2420 \\
\hline $\left.\begin{array}{l}\text { Bicarbonate } \\
(\mathrm{HCO}\end{array}\right)$ & 880 & Magnesium $(\mathrm{Mg})$ & 92 \\
\hline & & Aluminium $(\mathrm{Al})$ & 5.17 \\
\cline { 3 - 4 } & Barium $(\mathrm{Ba})$ & 0.385 \\
\cline { 2 - 4 } & Boron $(\mathrm{B})$ & 2.1 \\
\hline
\end{tabular}

COD - Chemical Oxygen Demand; BOD - Biological Oxygen Demand; TOC - Total Organic Carbon; AOX - Absorbable Organic Halides

In this research, 6 different solutions were tested, prepared by mixing leachate fluid with distilled water. Concentrations in volume were $100 \%, 50 \%, 10 \%, 5 \%$, $1 \%$ and $0 \%$. These solutions were named as L100, L50, L10, L5, L1 and DW respectively.
The electrical conductivity and suction were measured in each solution. The solutions were also used in sample preparation to measure their electrical resistivity and suction.

\section{Experimental Methods}

\subsection{Samples preparation}

The samples for the electrical resistivity tests were prepared in a cylindrical PVC mold with $25 \mathrm{~mm}$ of internal diameter, $1 \mathrm{~mm}$ of thickness and $60 \mathrm{~mm}$ of height (Fig. 3). The molds were filled with sand and then they were completely submerged in leachate solutions for at less one week, to guaranty total saturation. The top and bottom of the molds were sealed with geotextile. The geotextile chosen is very permeable, allowing the fluid to enter the sample easily and preventing the sand exit. This geotextile was attached to the PVC with some tension to avoid changes in sample volume.

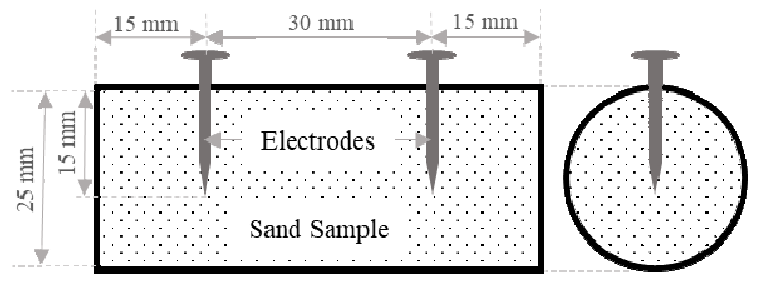

Fig. 3. Setup to measure electrical resistance of the samples.

Figure 3 also shows the configuration of the electrodes (stainless steel nails $1.5 \mathrm{~cm}$ depth) used for measuring the electrical resistivity of the sample. Electrodes were spaced $30 \mathrm{~mm}$ from each other, $15 \mathrm{~mm}$ from each end of the sample.

The samples for measuring the water potential were prepared with void ratio of 0.72 in the capsules used in WP4C equipment described latter. The complete water retention curve was measured only using distilled water, in which wetting was made by adding small drops of water using a syringe. For the drying branch, the sample was full saturated first and then drying was done by evaporation in controlled period of time. The amount of water present was controlled with a scale with $0.0001 \mathrm{~g}$ precision.

Identical samples were prepared using the solutions with different concentration of leachate, but for these fluids only two points were prepared following wetting: the first for $\mathrm{S}_{\mathrm{r}}=50 \%$ (degree of saturation below the residual degree of saturation of this soil, with still some continuity of water in the liquid phase in soil pores) and the second for the degree of saturation $S_{r}=100 \%$ (full saturation). This procedure intended to keep salt concentration constant, otherwise it would increase if evaporation on drying would occur.

\subsection{Electrical properties}

The electrical conductivity of the solutions prepared with leachate was measured with CRISON electronic device 
with a conductivity cell (range between $0.2 \mu \mathrm{S} / \mathrm{cm}$ and $200 \mathrm{mS} / \mathrm{cm}$ ) (Fig. 4).



Fig. 4. CRISON electronic device.

Concerning the contaminated sand samples, their electrical resistance was measured with the multimeter Keithley with a precision of $0.05 \Omega$ presented in Fig. 5, using the two electrodes previously presented in Fig. 3.

At least two measurements were done in each sample, after 30 and 60 seconds to reduce the time necessary for the readings and reproduce the time interval adopted in field measurements. Time had to be considered because of electrical capacitance, typical of soils. Capacitance is not expected to change for the different samples because the same materials was used in all samples, and therefore data measured using this time interval can be compared. The average value of electrical resistivity measured for the two instants was considered for all cases.

Electrical resistivity $\rho$ was found multiplying electrical resistance $\mathrm{R}$ measured by the space $\mathrm{L}$ between electrodes $(\mathrm{L}=30 \mathrm{~mm})$ (Eq. 1). This is a simplified procedure, used in all samples and therefore valid for comparison purposes.

$$
\rho=R L
$$

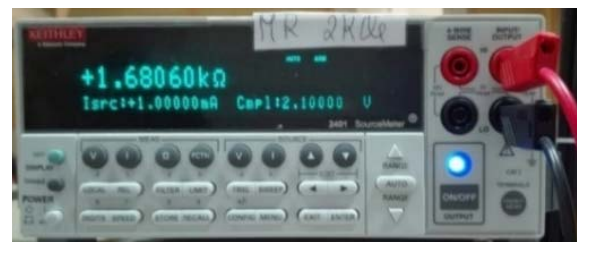

Fig. 5. Multimeter Keithley.

\subsection{Suction}

WP4C equipment was used (Fig. 6) for suction measurement [4]. The WP4C equipment measures total suction (sum of osmotic suction and matric suction), ranging from 0 to $-300 \mathrm{MPa}$ with an accuracy of \pm 0.05 $\mathrm{MPa}$ from 0 to $-5 \mathrm{MPa}$ and $1 \%$ from -5 to $-300 \mathrm{MPa}$. In this paper suction or water potential is plotted with positive values for simplification.

The water retention curve (WRC) of APAS 20 sand was measured in small sand samples prepared with distilled water in wetting and drying paths. In the wetting paths water was added in controlled manner using a syringe, while it was let evaporated in drying. The samples wetted were closed, sealed with isolation tape and left 24 hours to reach equilibrium before the measurements. For the drying branch, the fluid was added to complete saturate the sand and drying was done by evaporation in controlled period of time. After this time the samples were sealed as mentioned before.

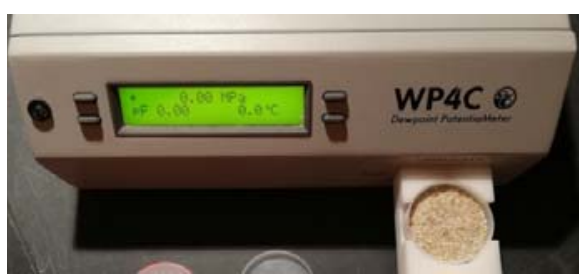

Fig. 6. Equipment WP4C.

This procedure was repeated in identical samples of sand to which the leachate solution was added instead of distilled water. The fluid concentration was controlled only in wetting paths because it was controlled by the fluid. This concentration was not controlled in the following drying. Complete drying was considered when the difference of weight measurements between 24 hours were less than $0.001 \mathrm{~g}$.

The equipment was used to measure the suction of the leachate solutions as well. This is also the procedure followed for its calibration before starting the measurements. In this study WP4C equipment was calibrated with $0.4 \mathrm{M}$ Sodium Chloride solution, that have a suction of $1.793 \mathrm{MPa}$ following the standard procedure from the manufacturer Decagon Devices, Inc. [4]. Suction measurements were corrected by using equation from Cardoso and co-authors [5], where $\psi$ is the sample suction, $\psi_{c a l}$ is the calibration point, $\psi_{W P 4 C}$ is the value measured and $b$ is a constant $(b=0.993)$.

$$
\psi=\psi_{W P 4 C}-\left(\psi_{W P 4 C}-\psi_{c a l}\right)\left(1-\frac{1}{b}\right)
$$

The equipment measures total suction, it is the sum of matric and osmotic suction in the soil samples, and osmotic suction in the fluids alone (because matric suction in this last case is null).

Experimental data from the WP4 allows determining the water retention curve (WCR), which relates total suction with the degree of saturation or the water content. Van Genuchten equation (Eq. 3) [6], was used to fit this data.

$$
S_{r}=\frac{G_{s}}{e} w=\left[\left(1+\frac{\psi}{P}\right)^{\frac{1}{1-\lambda}}\right]^{-\lambda}
$$

In eq. $3 \mathrm{~S}_{\mathrm{r}}$ is the degree of saturation, $\mathrm{G}_{\mathrm{s}}$ is specific gravity, e is the void ratio, $w$ is the water content, $\psi$ is the suction, $\mathrm{P}$ is the air-entry value and $\lambda$ is a shape parameter. Void ratio was constant during wetting and drying, as expected because the material is a sand.

\section{Results}

\subsection{Electrical resistivity}

Electrical resistivity measurements are shown in Table 2 for the leachate solutions (L samples) and sand samples 
saturated with these solutions (L+sand $\mathrm{S}_{\mathrm{r}}=100 \%$ samples). The same results are in Figure 7.

Table 2. Electrical resistivity of the solutions having different concentration of leachate and the saturated sand samples.

\begin{tabular}{|c|c|c|}
\hline Solution & $\begin{array}{c}\text { Electrical } \\
\text { resistivity of the } \\
\text { solutions }(\Omega \cdot \mathrm{m})\end{array}$ & $\begin{array}{c}\text { Electrical resistivity of } \\
\text { the soil samples } \\
\left(\mathrm{S}_{\mathrm{r}}=100 \%\right)(\Omega \cdot \mathrm{m})\end{array}$ \\
\hline TW & 61.65 & 785.25 \\
\hline L1 & 19.92 & 420.60 \\
\hline L5 & 4.85 & 263.24 \\
\hline L10 & 2.68 & 248.03 \\
\hline L50 & 0.65 & 35.58 \\
\hline L100 & 0.33 & 30.00 \\
\hline
\end{tabular}

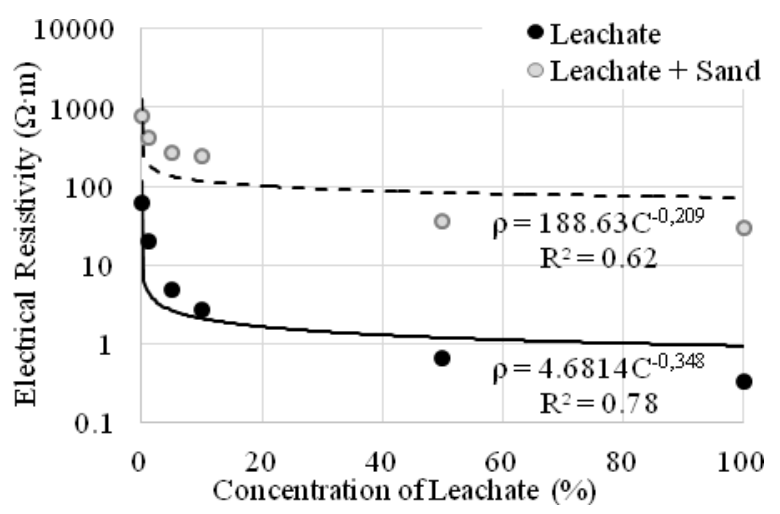

Fig. 7. Comparison of the electrical resistivity measurements for the solutions and for the full saturated sand samples.

As shown in Figure 7, the measurements performed in the two different kind of samples can be adjusted by a power function ( $\mathrm{C}$ is the concentration). The curves are almost parallel (exponents closer to -0.25), which allows concluding that the differences in electrical resistivity are due to the presence of the sand matrix, increasing the electrical resistivity mainly due the increasing of tortuosity of current flow without changing pore fluid composition.

\subsection{Water retention curve}

The water retention curve measured with distilled water is presented in Figure 8. It can be seen that the water content corresponding to $\mathrm{S}_{\mathrm{r}}=50 \%(\mathrm{w}=14 \%)$ is below the inflexion point identifying the residual degree of saturation [7]. By this manner there is continuity of the liquid phase [8], important for electrical current to flow.

Figure 8 also includes the curves for the wetting and drying branches found using eq. 3 . It is worth to note that scattering is expected for the low suction ranges investigated due to WP4C limitations. Calibration parameters $\lambda$ and $\mathrm{P}$ are in Table 3 .

Table 4 presents the suction measured in the solutions prepared with different concentration of leachate ( $\mathrm{L}$ samples). This is osmotic suction. As observed, suction increases with leachate concentration as it was expected.

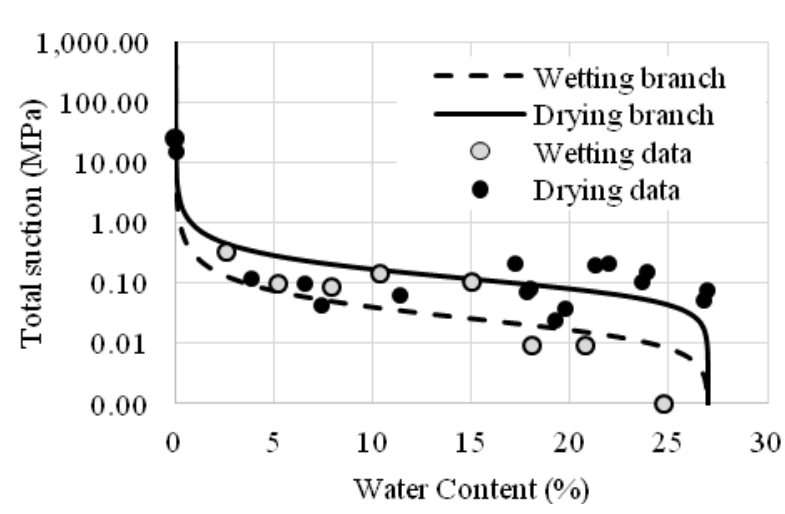

Fig. 8. Water retention curve (measured with distilled water).

Table 3. Calibration parameters of the water retention curve.

\begin{tabular}{|c|c|c|}
\hline & Drying branch & Wetting branch \\
\hline$\lambda(-)$ & 0.60 & 0.55 \\
\hline $\mathrm{P}(\mathrm{MPa})$ & 0.10 & 0.02 \\
\hline
\end{tabular}

Table 4. Suction measured in the solutions and in soil samples prepared with different concentrations of leachate.

\begin{tabular}{|c|c|c|c|c|}
\hline \multirow{2}{*}{ Solution } & \multirow{2}{*}{$\begin{array}{c}\text { Suction } \\
\text { of the } \\
\text { solutions } \\
(\mathrm{MPa})\end{array}$} & \multicolumn{3}{|c|}{$\begin{array}{c}\text { Suction of the soil samples } \\
\text { prepared with the fluids }\end{array}$} \\
\cline { 3 - 5 } & $\begin{array}{c}\mathrm{S}_{\mathrm{r}}=0 \% \\
\mathrm{w}=0 \%\end{array}$ & $\begin{array}{c}\mathrm{S}_{\mathrm{r}}=50 \% \\
\mathrm{w}=14 \%\end{array}$ & $\begin{array}{c}\mathrm{S}_{\mathrm{r}}=100 \% \\
\mathrm{w}=27 \%\end{array}$ \\
\hline DW & 0.00 & 26.33 & 0.01 & 0.00 \\
\hline L1 & 0.00 & 26.03 & 0.21 & 0.00 \\
\hline L5 & 0.01 & 47.23 & 0.06 & 0.16 \\
\hline L10 & 0.15 & 71.51 & 0.29 & 0.24 \\
\hline L50 & 0.78 & 58.58 & 1.02 & 0.56 \\
\hline L100 & 0.81 & 63.24 & 0.97 & 0.69 \\
\hline
\end{tabular}

The values measured in the sand samples to which these solutions were added are also in Table 4. In general, suction decreases with increasing degree of saturation and also with increasing leachate concentration.

These measurements were included in Figure 9, in which the wetting branch of the WRC measured with distilled water is also included.



Fig. 9. Wetting branch and suction measured in the sand samples to which the different fluids were added. 
It can be seen in Figure 9 that the points of the samples with the leachate solutions are above those measured with distilled water, and also above the wetting branch of the WRC.

For $\mathrm{S}_{\mathrm{r}}=50 \%(\mathrm{w}=14 \%)$ the values measured for the lowest concentrations of leachate (1, 5 and 10\%) are within the error of measurements done in the samples prepared using only distilled water. However for $\mathrm{S}_{\mathrm{r}}=100 \%$ only the solution with $1 \%$ of leachate approaches the wetting branch of the WRC. This must be because of the small amount of ions present for such low percentage.

\section{Discussion}

\subsection{Osmotic suction}

APAS 20 sand does not have minerals soluble in distilled water, therefore osmotic suction in the other sand samples is due to the pore fluid only. Considering that total suction $\psi$ is the sum of matric $\psi_{\mathrm{m}}$ and osmotic suction $\psi_{\text {os }}$ (Eq. 4), the suction measured in the samples prepared with distilled water is equal to matric suction and therefore osmotic suction can be computed using the values measured in the samples prepared with water and those measured in the other samples.

$$
\psi=\psi_{\mathrm{m}}+\psi_{\mathrm{os}}
$$

The values of osmotic suction computed with eq. 4 for each concentration of leachate are in Figure 10 only for the samples with $\mathrm{S}_{\mathrm{r}}=50 \%$ and $100 \%$. The horizontal lines in this figure are the values of the electrical resistivity of the solutions alone, also measured with WP4C. They are osmotic suction as well.



Fig. 10. Osmotic suctions computed for the sand samples to which the solutions of leachate were added (single points) and measured on the solutions (horizontal lines).

For the soil samples prepared with these solutions, the average osmotic suctions found are higher for the largest concentrations of leachate than for the smallest ones, as expected. Fixing the concentration of leachate, the values measured in the soil samples are almost constant for the two degrees of saturation investigated. They are similar to the values measured in the respective solutions. It is worth to note that WP4C equipment has error in the readings below $1-0.5 \mathrm{MPa}$, however the results are consistent and therefore this error can be considered not affecting the results in significant manner.

Figure 11 presents the evolution of osmotic suction as function of leachate concentration for the sand samples prepared with the two degrees of saturation, and also for the solutions alone. In general, osmotic suction increases with leachate concentration and this increment is independent from the degree of saturation of the sand samples.

Apart from some perturbation for the low percentages of leachate, it can be confirmed that osmotic suction measured in the samples prepared with the solutions and in the solutions alone is practically the same and independent from the degree of saturation.

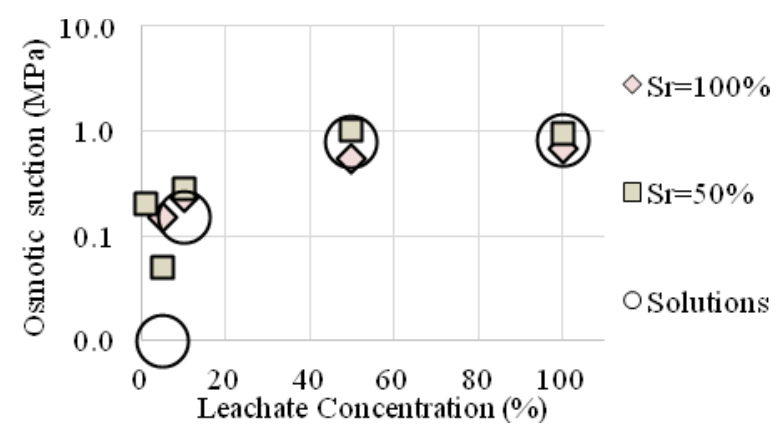

Fig. 11. Osmotic suctions vs concentration of leachate.

\subsection{Resistivity vs osmotic suction}

Electrical resistivity and osmotic suction are proprieties that depend on the amount of ions dissolved on the fluid sample or on the pore fluid of a sand sample. For the case studied, the amount of ions dissolved was controlled by the concentration of leachate in the solution added to the sand samples. The relationship between electrical resistivity and osmotic suction is presented in Figure 12 for the full saturated samples. As expected, the electrical resistivity decreases with increasing osmotic suction.

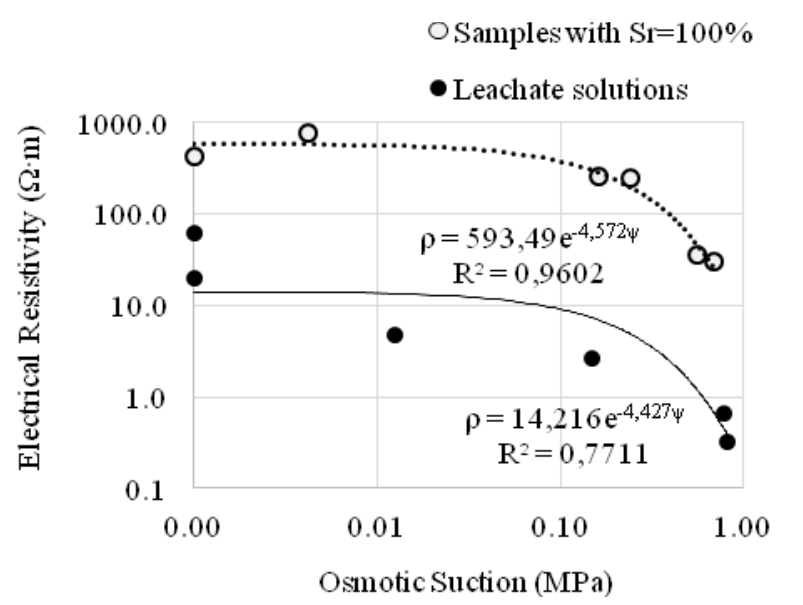

Fig. 12. Electrical resistivity vs osmotic suction for the full saturated samples. 
Both series of data can be adjusted by an exponential function also in Figure 12, which confirms that electrical resistivity and osmotic suction are related, as well known.

Data about the electrical resistivity of the samples with $\mathrm{S}_{\mathrm{r}}=50 \%$ are non-existent, but the values will increase significantly because there is the influence of the degree of saturation. Previously it was seen that the osmotic suction was not affected by the degree of saturation (Fig. 11), therefore the electrical resistivity dependence on the degree of saturation is not affected by the pore fluid composition. It will be affected by liquid presence and its continuity in the soil. This is related with soil structure and not to electrochemical effects.

The exponents of the fitting curves in Fig. 12 are quite similar (around -4.5), so the gap between these curves found for the saturated soil and for the solutions alone can only be justified by the presence of the solid particles, affecting electrons path through the material. A similar pattern was observed when electrical resistivity dependence on solutions concentration was investigated, previously presented in figure 7 (exponents around -0.25). The gaps between the curves of the two figures are translated by the well known formation factor from Archie's law [9], $F F$, which is the electrical resistivity of the saturated soil, $\rho$, divided by the electrical resistivity of the pore fluid, $\rho_{f}$. The other terms of this law (Eq. 5) are constant $a$, porosity $n$ and constant $m$, related with soil physical parameters.

$$
F F=\frac{\rho}{\rho_{f}}=a n^{-m}
$$

Although only one void ratio was investigated, one attempt can be made to find constants $a$ and $m$ if $m$ is assumed to be between 1 and 3 [9], the interval of values typical of sands. For $m=2$ and $n=0.422$ (e=0.72), $a=7.17$ or $a=7.43$ if data from figures 9 or 12 are considered. These values are similar and the average value $a=7.3$ be considered. This is value is also typical of sands $[9,10]$. The similarity of the values found confirm that electrical resistivity and osmotic suction are related when fixing soil structure (given by porosity and $m$ ).

\section{Conclusions}

The osmotic suction and electrical resistivity were measured for uniform grading size samples of sand prepared with solutions having different concentrations of an ionic leachate from a real landfield, and also for the solutions alone.

The sand matrix had a main influence increasing the electrical resistivity of the full saturated samples due the increasing of tortuosity in electrons flow. The soil osmotic suction is similar to the osmotic suction of the pore fluid independently from the degree of saturation of the soil samples.

Being the osmotic suction identical for the saturated and unsaturated samples, the increment typically observed in electrical resistivity when the degree of saturation decreases is due to the presence of liquid phase and its continuity in soil pores. Therefore, although pore fluid composition affects electrical resistivity, when evaluating the electrical resistivity considering the degree of saturation one should pay attention to soil structure. This is considered also when matric suction is investigated, and therefore when relating electrical resistivity and suction, if osmotic effects are known only matric suction should be considered.

Another important conclusion is that electrical resistivity appears to be better to be used for soil osmotic suction measurements instead of total suction because it will not be affected by the degree of saturation of the sample. However a minimum degree of saturation must be defined to allow the measurements. A starting point can be considering the residual degree of saturation determined from the water retention curve.

\section{Acknowledgments}

The authors acknowledge funding from FCT I.P. project BIOSOIL PTDC/ECI-EGC/32590/2017. Acknowledgement is also due to AMARSUL for supplying the leachate fluid used.

\section{References}

1. A.N. Alshawabkeh, A. T. Yeung and M.R. Bricka, Journal of Environmental Engineering, 125(1), 2735 (1999)

2. D Gunn, J.E. Chambers, S. Uhlemann, P.B. Wilkinson, P.I. Meldrum, T. Dijkstra, E. Haslam, M. Kirkham, J. Wragg, S. Holyoake, P.N. Hughes, R. Hen-Jones and S. Glendinning, Constr. Build. Mat., 92, 82-94 (2014)

3. D.G. Fredlund and H. Rahardjo, Soil Mechanics for Unsaturated Soils. (John Wiley and Sons, New York, 1993)

4. Decagon Devices, Inc. WP4 Water Dewpoint Potentiometer. Operator's Manual Version 2.2. (Decagon Devices, Inc., Pullman, USA, 2003)

5. R. Cardoso, E. Romero, A. Lima, and A. Ferrari, Experimental Unsaturated Soil Mechanics, Springer Proceedings in Physics, 112, 79-94 (2007)

6. M.T. van Genuchten, Soil Sci. Soc. Am. J. 44, 892898 (1980)

7. R. Cardoso and S. Dias, Engineering Geology, 226, 1-11 (2017)

8. S.K. Vanapalli, D. Fredlund, D. G. and D.E. Pufahl, Géotechique, 49(2), 143-159 (1999)

9. G. Archie, Petroleum Transactions of the American Institute of Mineralogical and Metallurgical Engineers 146, 54-62 (1942)

10. D. Wildenschild, J.J. Roberts and E.D. Carlberg, Geophysical Research Letters, 27 (19), 3085-3088 (2000) 